\title{
Biodegradation of Anthracene Compound by Two Species of Filamentous Fungi
}

\author{
Duha Bahaa Mohammed ${ }^{1}$
}

\author{
Adnan H. Abbas ${ }^{2 *}$ \\ Ahmed M. Abed Ali
}

Received 26/9/2017

Accepted 7/1/2018

\author{
Eman H. Abed $^{3}$
}

\begin{abstract}
:
Isolation and identification fungi of Emericella nidulans and Aspergillus flavus from a pinkish and yellowish artificial clay, by using potato dextrose agar (PDA). Results revealed that $E$. nidulans was the best for degrading anthracene (92.3\%) with maximum biomass production $(3.7 \mathrm{gm} / \mathrm{l})$, compared to A. flavus with the rate of degradation (89\%) and biomass production of $(1.2 \mathrm{gm} / \mathrm{l})$, when methylene blue was used as redox indicator after incubating in a shaker incubator $120 \mathrm{rpm}$ at $30 \mathrm{C}^{\circ}$ for 8 days. Results indicated that E. nidulans has a high ability of anthracene degradation with the rate of (84\%), while A. flavus showed the lower level with $(77 \%)$ by using HPLC.
\end{abstract}

Keywords: Filamentous fungi, Anthracene biodegradation, Emericella nidulans, Aspergillus flavus.

\section{Introduction:}

Polycyclic aromatic hydrocarbons (PAHs) are prevalent environmental pollutants. Uptake of anthracene via numerous routes in the body imposes toxicity to the skin, blood, intestine and the lymphatic system, thus leading to tumors, edema, itching and the upsurge of fluids in tissues $(1,2)$.

Numerous procedures were utilized to expel PAHs, as physical treatment, chemicals and microbial degradation using bacteria, fungi, algae and yeasts $(3,4)$.

Anthracene is a solidify PAH $\left(\mathrm{C}_{14} \mathrm{H}_{10}\right)$, comprising about three combined Benzene rings. It will be utilized to prepare the Red Dye Alizarin and other dyes. Anthracene may be colorless, but display a blue (400-500)nm peak fluorescence under ultraviolet light (5).

Many literatures show that filamentous fungi are playing an important role in removing of PAHs and even more effective than some bacteria. Increasing non-ligninolytic fungi, Penicillium simplicissmum and species belonged to the genera Trichoderma, Fusarium, Penicillium, Stachybotrys, Aspergillus, Cladosporium, Mortierella, Beauveria and Engyodontium, have been recently described as tolerant to pollutants such as PCBs and chlorobenzoic acids (6).

1,2,3,4 Ministry of Science and Technology, Environment and Water Directorate, Baghdad, Iraq.

*Corresponding author: adn927an@gmail.com

\section{Materials and Methods:}

\section{The source of fungal isolates}

Fungal isolates were isolated from a yellowish and pinkish artificial clay.

\section{Purification of isolated fungi}

Fungus isolates were purified by repeat culturing on plates containing PDA medium, till ensuring purity of fungal isolates. Then isolates subsequently cultured on PDA slants and allowed to grow for 57 days stored at $4^{\circ} \mathrm{C}$ as stock cultures.

\section{Identification of fungal isolates}

A colony of fungal isolates were diagnosed due to their morphological characteristics by utilizing the lactophenol solution, then slides were recognized under the microscope.

\section{Methylene blue (Redox indicator)}

Erlenmeyer flasks (Volume 100ml) were used in this experiment containing a suitable amount of mineral salt medium preparing by Ameen et al., (2014) with some modification (7), containing $25 \mu 1$ of Tween 80, then volume flasks were completed to $25 \mathrm{ml}$ with the same media, $(\mathrm{pH} 7.0), 15 \mu \mathrm{l}$ of methylene blue as prepared by Wilson and Jones (8) and $100 \mathrm{ppm}$ anthracene were added after autoclaved media at $121^{\circ} \mathrm{C}$ for $15 \mathrm{~min}$. Flasks were inoculated with diameter $7 \mathrm{~mm}$ of selected fungal isolates (One isolate for each flask). Flasks were incubated in a shaker incubator $120 \mathrm{rpm}$ at $30 \mathrm{C}^{\circ}$ for 
8days. All experiments were done in duplicate and control for each isolate. After the incubation period, growth culture was filtrated to separate biomass, followed by centrifugation at 10000 rpm for $15 \mathrm{~min}$.
Supernatant was analyzed by spectrophotometer at $609 \mathrm{~nm}$ and the percentage of degradation was calculated by a formula as below (9).

$$
\begin{aligned}
& \% \text { of degradation }=1- \\
& \text { Absorbance of control }
\end{aligned}
$$

Estimation of anthracene concentration by HPLC

After a period of incubation, the growth was harvested at $10000 \mathrm{rpm}$ for $20 \mathrm{~min}$ and filtered through Whatman No. 1. Add $10 \mathrm{ml}$ of hexane to $25 \mathrm{ml}$ of supernatant, then mixing for $30 \mathrm{~min}$ by using separate funnel, then $1 \mathrm{ml}$ from the upper phase (Hexane) was transferred to a sterile tube for HPLC analysis, which achieved with reverse-phase column C18 (Syknm Chromatography Products, Germany). Separation was accomplished by isocratic elution in (Acetonitrile: Water) (70:30), with a flow rate $1.0 \mathrm{ml} / \mathrm{min}$ and $\mathrm{UV}$ absorbance detector set at $254 \mathrm{~nm}$.

$$
\begin{aligned}
& \text { Initial conc. of anthracene - Anthracene conc. after incubation } \\
& \text { Degradation= --- Initial conc. of anthracene }
\end{aligned}
$$

\section{Estimation of biomass}

Twenty-five $\mathrm{ml}$ of growth media was centrifuged with speed $10000 \mathrm{rpm}$ at $4^{0} \mathrm{C}$ for $20 \mathrm{~min}$, then supernatant was discarded and biomass washed 2-3 times with distilled water, re-centrifuge under the same conditions. Dry weight was estimated after drying at $80^{\circ} \mathrm{C}$ for $24 \mathrm{~h}(10]$.

\section{Results and Discussion: Identification of fungal isolates}

Morphological characteristics of fungal colonies by using a dissecting microscope, were the initial identification according to their macroscopic and microscopic features. Results showed that most active isolates were identified as $E$. nidulans and $A$. flavus (11) [Fig. 1, 2 (A\&B)].

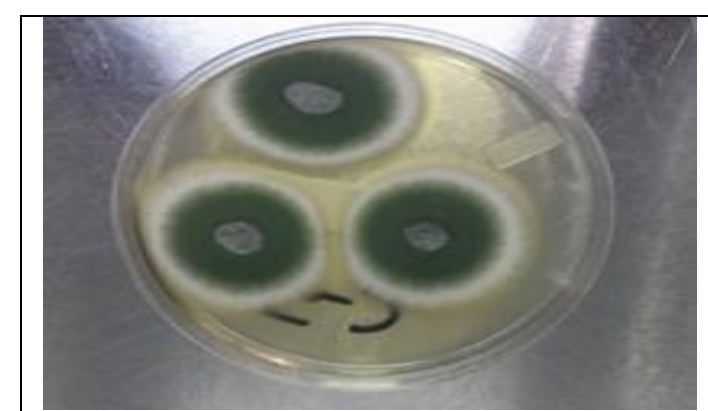

Figure 1-A. Macroscopic feature of $E$. nidulans, after growing on the PDA medium at $28^{\circ} \mathrm{C}$ for 7days.

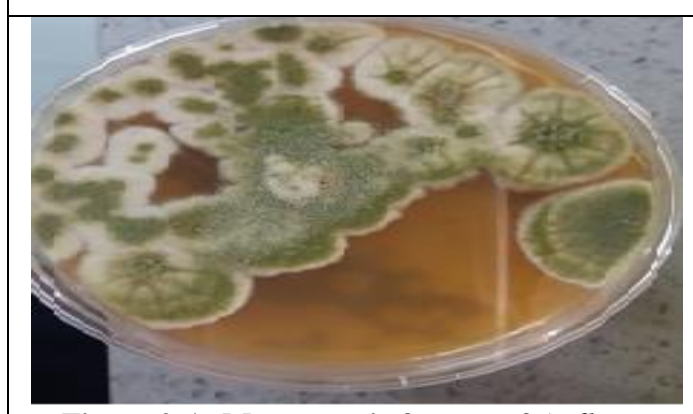

Figure 2-A. Macroscopic feature of A. flavus after growing on the PDA medium at $28^{\circ} \mathrm{C}$ for 7 days.

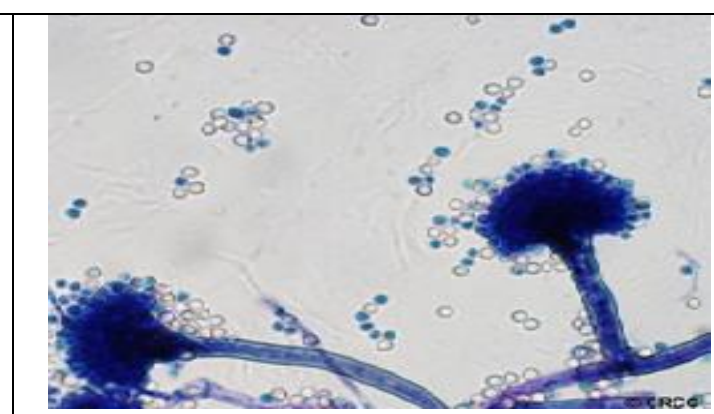

Figure 1-B. Microscopic feature of $E$. nidulans, (Staining with lactophenol solution) showing conidial head (40x).

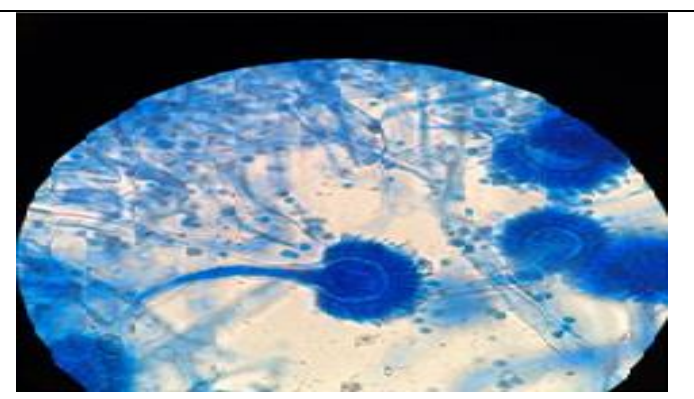

Figure 2-B. Microscopic feature of A. flavus (Staining with lactophenol solution) showing conidial head $(40 x)$.

\section{Biodegradation of anthracene}

The period of incubation was the most important factor that affects degradation processes (12) and the optimum condition for anthracene degradation (100ppm), by E. nidulans and A. flavus isolated 
from artificial clay, were incubated in a shaker incubator $120 \mathrm{rpm}$ at $30 \mathrm{C}^{\circ}$ for 8 days.

The result showed that increasing concentration of a water soluble synthetic compound (Tween 80) improved the biodegradation and bioremediation of toxic pollutants. Muthusamy et al., (13), just as (1, 2.5 and 5) $\mathrm{gm} / \mathrm{l}$ in the media create gradual increasing in decane biodegradation (55.0, 74.5 and 79.3)\%, respectively, at $20^{\circ} \mathrm{C}$. Whereas $10 \mathrm{gm} / \mathrm{l}$ of tween 80 caused decreases in biodegradation (57.2)\% compared to $5 \mathrm{gm} / \mathrm{l}(79.3) \%$ at the same degree.

We can be inferred that low nutrients, low $\mathrm{pH}$, accumulation of metabolites resulting from oxidation processes, lack oxygen and ventilation, were the reasons of decreasing anthracene degradation after 8days (14).

Ravelet et al., (15) recorded that Zygomycota Mucor racemosus was able to degrade more than $40 \%$ of anthracene after 8days of incubation. This result elucidates that biodegradation happened due to the higher surface area (Fungal mycelium), which increased both mechanical and enzymatic contacts with an insoluble substrate such as anthracene and invade a larger volume of soil (16). At the same time, Mohammed et al., (17) verified that degradation of anthracene by fungi are more practical than bacterial degradation.

\section{A- Methylene blue method}

The statistical results showed that E. nidulans was significantly the better isolate in degradation of anthracene compound by using methylene blue as a reduction agent to the residue of anthracene, with an OD 0.2 and rate $92.3 \%$, compared to an OD of $A$. flavus 0.3 and rate of degradation was $89 \%$ (Fig. 3) (Table 1).

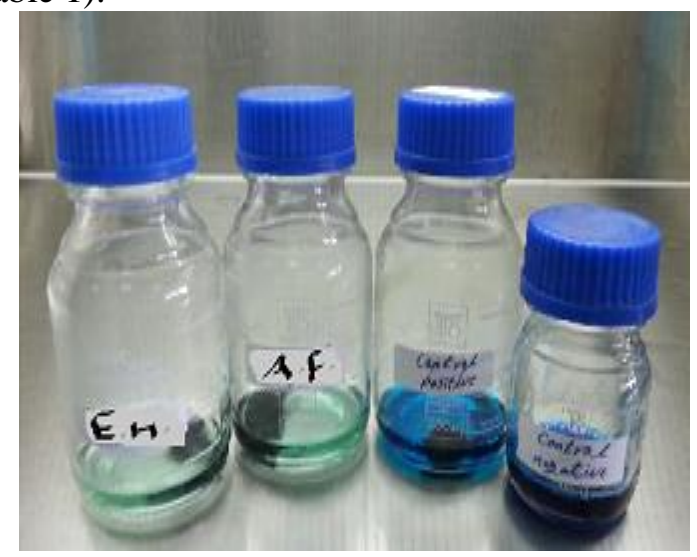

Figure 3. Reduction of methylene blue (Redox indicator) by $E$. nidulans and $A$. flavus after 8days of incubation in shaker incubator 120rpm at $30^{\circ} \mathrm{C}$.

The ability of these isolates to induce the color change in the media is presumably due to a reduction of the indicator by oxidized products of hydrocarbon degradation or due to the fungal growth, which utilizes oxygen for their metabolism (9). Results showed that Penicillium simplicissimum, Phanerochaete chrysosporium and Irpex lacteus, were degraded anthracene $(100 \mu \mathrm{M})$ after 61days of incubation, with ratio approximately (86, 40 and 38)\%, respectively (6).

Table 1. Reduction of methylene blue and percentage of anthracene degradation by $E$. nidulans and $A$. flavus after 8days in shaker incubator $120 \mathrm{rpm}$ at $30^{\circ} \mathrm{C}$.

\begin{tabular}{cccc}
\hline No. & Fungal isolates & Reduction of methylene blue (OD) & Degradation \% \\
\hline 1 & Control negative & 2.396 & 1.75 \\
2 & Control positive & 2.354 & 92.3 \\
3 & Emericella nidulans & 0.2 & 89 \\
4 & Aspergillus flavus & 0.3 & 9 \\
\hline
\end{tabular}

Control negative: (media, methylene blue and anthracene)

Control positive: (media, methylene blue and inoculum)

\section{B- Estimation of biomass method}

The results showed variation in the capacity of the fungal isolates in the consumption of anthracene in the liquid mineral salts media. It was found that the pink colony ( $E$. nidulans) was the best isolate for anthracene degradation with the rate of $84 \%$ and yield maximum biomass $3.7 \mathrm{gm} / 1$, while the yield maximum biomass of yellow colony (A. flavus) was $1.2 \mathrm{gm} / \mathrm{l}$, with the rate of anthracene degradation reaching to $77 \%$ (Table 2).

Table 2. Biomass yield and anthracene degradation by $A$. flavus and $E$. nidulans isolates in liquid mineral salts medium with $100 \mathrm{ppm}$ anthracene after 8days in shaker incubator $120 \mathrm{rpm}$ at $30^{\circ} \mathrm{C}$

\begin{tabular}{cccc}
\hline No. & Fungal isolates & Biomass yield gml & Anthracene degradation \% \\
\hline 1 & Control & 3.80 & 1.752 \\
2 & Emericella nidulans & 3.7 & 84 \\
3 & Aspergillus flavus & 1.2 & 77 \\
\hline
\end{tabular}

Control: (media without inoculum) 
Results showed that there is a relationship between rates of anthracene consumption concentrations and biomass production. E. nidulans was the best isolate that decreases anthracene concentration and produces maximum biomass. Garapati and Mishra (18) were used Penicillium sp. and Aspergillus versicolor upon growth in liquid medium containing 500ppm of crude oil, they recorded that these isolates increase in biomass $(2.3$ and 2.56)gm/l, respectively, according to decrease in crude oil concentration with a rate of degradation (76.5 and 78.4)\%, respectively.

Biomass of Stereum ostrea and Phanerochaete chrysosporium growing in liquid medium contains $1 \%$ anthracene under shaking conditions, were initially slow for 4days, then picked up and remained steady at 8days of incubation. Stereum ostrea produced maximum biomass of $1.89 \mathrm{gm} / \mathrm{flask}$ $(25 \mathrm{ml})$ after 8days of incubation with anthracene degradation $62.3 \%$, while the fungus Phanerochaete chrysosporium gave $1.78 \mathrm{gm} / \mathrm{flask}$ $(25 \mathrm{ml})$ with anthracene degradation $56.6 \%$ over the same period of incubation (19).

\section{References}

1. Dong DM, Liu XX, Hua XY, Guo ZY, Li LF, Zhang LW, Xie YJ. Sedimentary record of polycyclic aromatic hydrocarbons in Songhua River. China Environ Earth Sci. 2016; 75(6): 508-515.

2. Wieczorek J, Sienkiewicz S, Pietrzak M, Wieczorek Z. Uptake and phytotoxicity of anthracene and benzo [k] fluoranthene applied to the leaves of celery plants (Apium graveolens var. secalinum L.). Ecotoxicol Environ Saf. 2015 February; 115: 19-25.

3. Krachai N, Hadjel M. Characterization and treatment of contaminated marine sediments for reuse. Desalination Water Treat. 2013 December; 1-6.

4. Niu J, Dai Y, Guo H, Xu J, Shen Z. Adsorption and transformation of PAHs from water by a laccaseloading spider-type reactor. J. Hazard Mater. 2013 January; 248-249: 254-260.

5. Maiti A, Das S, Bhattacharyya N. High gelatinase activity of a newly isolated polycyclic aromatic hydrocarbon degrading bacteria Bacillus weihenstephanensis strain AN1. J Pharm Res. 2013; 6(1): 199-204.

6. Patricia J, Maria A, Olivella S, Josep C, Carles C, Laura P, Francesc CX, Delas H. Fungal biodegradation of anthracene-polluted Cork: A comparative study. J Environm Sc HeaI. Part A. 2016; 51(1): 70-77.
7. Ameen F, Moslem MA, Hadi S, Al-Sabri A. Biodegradation of cellulosic materials by marine fungi isolated from South Corniche of Jeddah, Saudi Arabia. J Pure Appl Microbiol. 2014; 8(5): 36173626.

8. Wilson SC, Jones KC. Bioremediation of soil contaminated with poly nuclear aromatic hydrocarbons (PAHs): a review. Environmental Pollution. 1993; 81(3): 229-249.

9. Hari S. Isolation and screening of hydrocarbon degrading fungi from soil. Applied Microbiology and Biotechnology. 2003; 22: 112-115.

10. Boyle CD, Kropp R. Development and comparison of methods for measuring growth of filamentous fungi on wood. Can J Microbiology. 1992; 38(10): 10531060.

11. Samson RA, Hoekstra ES, Frisvad JC, Filtenborg O. Introduction to food-borne fungi. Sixth edition. Centraalbureau voor Schimmelcultures. 2000; pp. 389.

12. Atlas RM. Microbial Degradation of Petroleum Hydrocarbons: An Environmental Perspective. Microbiology Rev. 1981March; 45(1): 180-209.

13. Muthusamy G, Soichiro F, Toshiki H, Young-Cheol C. Biodegradation of aliphatic and aromatic hydrocarbons using the filamentous fungus Penicillium sp. CHY-2 and characterization of its manganese peroxidase activity. RSC Adv. 2017 April; 7: 20716-20723.

14. Bishnoi K, Kumar R, Bishnoi NR. Biodegradation of polycyclic aromatic hydrocarbons by white rot fungi Phanerochaete chrysosporium in sterile and unsterile soil. Journal of Scientific and Industrial Research. 2008; 67 (7): 538-542.

15. Ravelet C, Krivobok S, Sage L, Steiman R. Biodegradation of pyrene by sediment fungi. Chemosphere. 2000 March; 40(5): 557-563.

16. Potin O, Rafin C, Veignie E. Bioremediation of an aged polycyclic aromatic hydrocarbons (PAHs) contaminated soil by filamentous fungi isolated from the soil. Inter Biodet Biodeg. 2004; 54(1): 45-52.

17. Mohammed AR, Hashem AM, Amin MA, Rfky NH. Immobilization and surfactant enhanced anthracene biodegradation in soil. J Amer Sci. 2012; 8(3): 596602.

18. Garapati VK, Mishra S. Hydrocarbon Degradation Using Fungal Isolates: Nutrients Optimized By Combined Grey Relational Analysis. Int. J. Eng. Res. Appl., 2012; 2(2): 390-399.

19. Ekpo MA, Udofia US. Fate of biodegradation of crude oil by microorganisms isolated from oil sludge environment. African Journal of Biotechnology. 2008; 7(24): 4495-4499. 


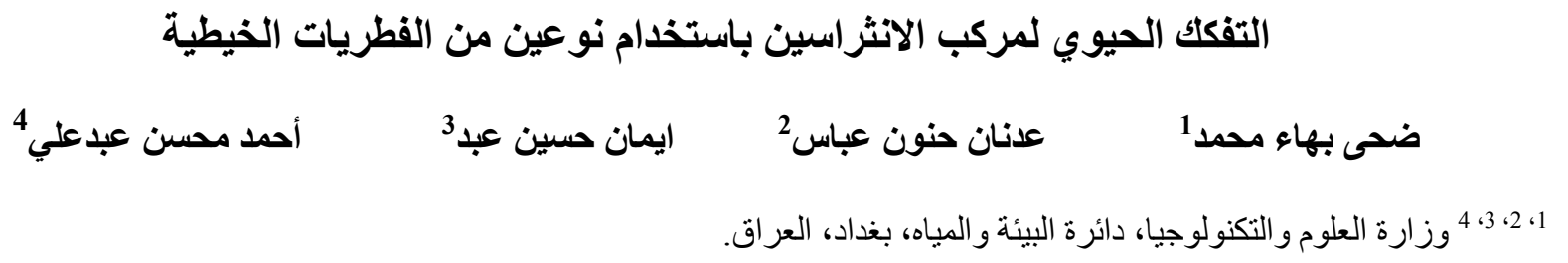

الخلاصة:

عزلت وشخصت عزلتين من الفطريات Aspergillus flavus و من الطين الاصطناعي الوردي والاصفر

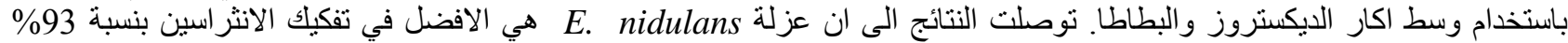

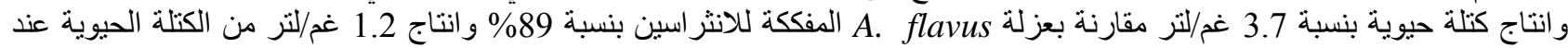

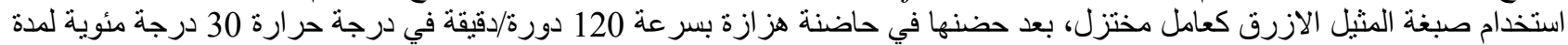

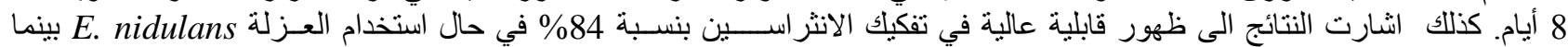

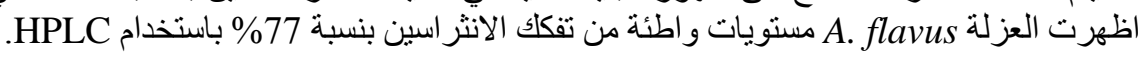

الكلمات المفتاحية: الفطريات الخيطية، التفكك الحيوي للانثراسين، الفطر Aspergillus flavus ‘Emericella nidulans. 